\title{
The endocannabinoid system is modulated in reward and homeostatic brain regions following diet-induced obesity in rats: a cluster analysis approach
}

\author{
Romain Bourdy ${ }^{1} \cdot$ Alexandra Hertz $^{1} \cdot$ Dominique Filliol $^{1} \cdot$ Virginie Andry $^{2}$. Yannick Goumon ${ }^{2}$. Jorge Mendoza ${ }^{2}$. \\ Mary C. Olmstead ${ }^{3} \cdot$ Katia Befort $^{1}$ (1)
}

Received: 13 January 2021 / Accepted: 8 June 2021 / Published online: 24 June 2021

(c) Springer-Verlag GmbH Germany, part of Springer Nature 2021

\begin{abstract}
Objectives Increased availability of high-calorie palatable food in most countries has resulted in overconsumption of these foods, suggesting that excessive eating is driven by pleasure, rather than metabolic need. The behavior contributes to the rise in eating disorders, obesity, and associated pathologies like diabetes, cardiac disease, and cancers. The mesocorticolimbic dopamine and homeostatic circuits are interconnected and play a central role in palatable food intake. The endocannabinoid system is expressed in these circuits and represents a potent regulator of feeding, but the impact of an obesogenic diet on its expression is not fully known.

Methods Food intake and body weight were recorded in male Wistar rats over a 6-week free-choice regimen of high fat and sugar; transcriptional regulations of the endocannabinoid system were examined post-mortem in brain reward regions (prefrontal cortex, nucleus accumbens, ventral tegmental area, and arcuate nucleus). K-means cluster analysis was used to classify animals based on individual sensitivity to obesity and palatable food intake. Endocannabinoid levels were quantified in the prefrontal cortex and nucleus accumbens. Gene expression in dopamine and homeostatic systems, including ghrelin and leptin receptors, and classical homeostatic peptides, were also investigated.

Results The free-choice high-fat -and sugar diet induced hyperphagia and obesity in rats. Cluster analysis revealed that the propensity to develop obesity and excessive palatable food intake was differently associated with dopamine and endocannabinoid system gene expression in reward and homeostatic brain regions. CB2 receptor mRNA was increased in the nucleus accumbens of high sugar consumers, whereas CB1 receptor mRNA was decreased in obesity prone rats.

Conclusions Transcriptional data are consistent with observations of altered dopamine function in rodents that have access to an obesogenic diet and point to cannabinoid receptors as GPCR targets involved in neuroplasticity mechanisms associated with maladaptive intake of palatable food.
\end{abstract}

Keywords Endocannabinoids $\cdot$ Diet-induced obesity $\cdot$ Reward $\cdot$ Dopamine $\cdot$ Gene expression $\cdot$ Mass spectrometry

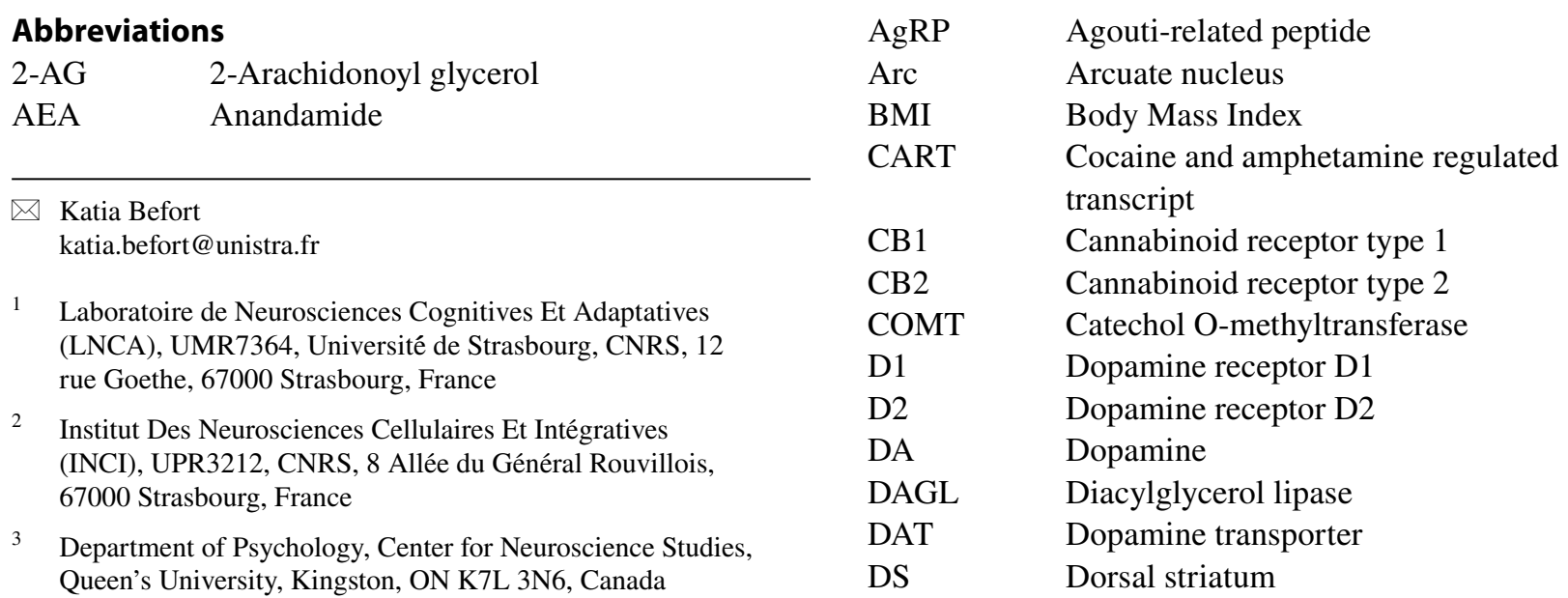




$\begin{array}{ll}\text { FAAH } & \text { Fatty acid amide hydrolase } \\ \text { GPCR } & \text { G protein-coupled receptor } \\ \text { GPR55 } & \text { G protein-coupled receptor 55 } \\ \text { GR } & \text { Growth hormone secretagogue receptor } \\ \text { HFC } & \text { High Fat Consumers } \\ \text { HSC } & \text { High Sucrose Consumers } \\ \text { LPC } & \text { Low Palatable Consumers } \\ \text { LR } & \text { Leptin receptor } \\ \text { MGL } & \text { Monoacylglycerol lipase } \\ \text { NAc } & \text { Nucleus accumbens } \\ \text { NAPE-PLD } & \text { N-acyl phosphatidylethanolamine phospho- } \\ & \text { lipase D } \\ \text { NPY } & \text { Neuropeptide Y } \\ \text { OP } & \text { Obesity Prone } \\ \text { OR } & \text { Obesity Resistant } \\ \text { PFC } & \text { Prefrontal cortex } \\ \text { POMC } & \text { Proopiomelanocortin } \\ \text { TH } & \text { Tyrosine hydroxylase } \\ \text { VTA } & \text { Ventral tegmental area }\end{array}$

\section{Introduction}

Obesity has increased worldwide in the past few decades and represents one of the biggest contemporary health challenges. The condition is associated with severe health problems, such as Type 2 Diabetes, hypertension, cardiovascular diseases, and multiple cancers [1]. Most recently, obesity has been identified as a primary risk factor for poor outcomes related to Coronavirus disease [2]. Increased availability of low cost, energy-dense food and sugary drinks is a major contributor to overeating, which is the largest determinant of obesity [3]. Interestingly, ingestion of palatable food activates brain reward systems and shares common mechanisms of action with drugs of abuse. These could explain a switch from controlled to excessive food intake that leads to obesity, although the possibility that "addiction" develops to palatable food remains controversial [4].

Food intake is regulated by a complex interplay between peripheral physiological signals and brain reward circuits [5]. These interactions involve metabolic and nutritional signals that regulate homeostatic eating and reward signals coding pleasurable aspects of food that drive hedonic intake. More specifically, the homeostatic system maintains energy balance between caloric intake and energy expenditure. This system is located in the mediobasal hypothalamus including the arcuate nucleus (Arc), which contains two distinct subsets of neurons. The first expresses pro-opiomelanocortin (POMC) and cocaine-amphetamine-regulated transcript (CART) and suppresses feeding while increasing metabolic rate. The second expresses neuropeptide Y (NPY) and agouti-related peptide (AgRP) which increases food intake. These are under the control of peripheral signals, including ghrelin and leptin that convey information to the brain regarding available energy stores, then initiate adaptive behaviors (i.e., food intake) in response to deficits [6]. Hedonic feeding is mediated via the reward system, consisting of mesolimbic dopamine (DA) projections from the ventral tegmental area (VTA) to the nucleus accumbens (NAc) and prefrontal cortex (PFC). Drugs of abuse and highly palatable food both increase DA release in the NAc [7, 8], leading to overlapping neuroadaptations in reward circuitry that alter the motivation to obtain a reward [9]. Both obese humans and animals, that have undergone excessive food intake, exhibit altered reward processing [10, 11]. Among suggested mechanisms, heightened cue reactivity has been proposed to predispose individuals to overeat. Compulsive eating may also result from this alteration combined with deficient prefrontal inhibitory circuits $[12,13]$. Another hypothesis proposes that a hypofunctioning reward system increases consumption of highly palatable food; in this case, excessive food intake is a compensatory mechanism to deal with diminished rewarding effects of palatable food [11, 14, 15]. These results converge on the idea that a DA deficiency syndrome (i.e., hypodopaminergic function) underlies excessive eating that leads to obesity.

In addition to DAergic systems, regulation of food intake and energy balance involves other systems, including the endocannabinoid system [16]. Centrally, this system is composed of two well-characterized G-protein coupled receptors (CB1 and $\mathrm{CB} 2)$. Other receptors, including the orphan GPR55, are also targets of cannabinoid compounds. Endogenous compounds that act at these receptors have been described, with the best studied being anandamide (AEA) and 2-arachidonoylglycerol (2AG). The system is expressed both in hypothalamic and mesolimbic brain regions where it regulates both homeostatic and hedonic feeding [17]. In the hypothalamus, endocannabinoid levels are modulated in response to metabolic states with an increase during fasting and a decrease when animals are sated [16]. Endocannabinoids in the NAc and VTA modulate palatable food-evoked DA release $[18,19]$, increasing palatability and the hedonic impact of food [20]. As in the hypothalamus, food deprivation increases endocannabinoid levels whereas food consumption decreases these in the limbic forebrain, including the NAc [21]. Indeed, endocannabinoids promote overeating when administered centrally either in the hypothalamus or the NAc [21, 22]. The endocannabinoid system, therefore, links homeostatic and hedonic circuits involved in energy balance regulation [17], which may explain cannabinoid signal dysfunction in eating disorders and obesity [23]. Indeed, obesity is associated with an overactive endocannabinoid system in humans and animal models, including elevated plasmatic levels of AEA and 2-AG [24-26].

One diet-induced obesity rodent model, based on a freechoice high-fat high-sucrose (fcHFHS) paradigm, has proven 
to be a valuable preclinical model for obesogenic studies as it induces caloric overconsumption and excessive weight gain (for a review, see [27]). In this paradigm, rodents have the opportunity to choose from several diet components, heterogeneous in palatability, form and nutritive content [28], which mimics an important feature of modern-day human diets. Extended exposure to this fcHFHS diet increases motivation to work for sugar pellets, an effect not observed following no choice diets [29]. Interestingly, this increased motivation occurs specifically in obesity prone rats following food withdrawal [30]. We used this paradigm to investigate the consequences of a fcHFHS diet on gene expression in DA and endocannabinoid systems using qPCR; we focused on brain regions associated with homeostatic and hedonic control of food intake. A k-means cluster analysis approach was used to analyze these data, based on obesity or palatable food intake hallmarks. Furthermore, endocannabinoid levels were measured in both the NAc and PFC using mass spectrometry.

\section{Methods}

\section{Subjects}

Forty-eight male Wistar rats (Janvier Labs, Le Genest-SaintIsle, France) weighing $200 \pm 10 \mathrm{~g}$ at arrival were individually housed in standard cages in a light-controlled room (lights on 07:00-19:00) maintained at a temperature of $23{ }^{\circ} \mathrm{C}$. Rats were allowed to adapt to their environment for 2 weeks with access to ad libitum standard chow (Standard Diet, Mucedola, Italy) and water. All experiments were approved by the CREMEAS (Comité d'Éthique pour l'Expérimentation Animale de Strasbourg, France, APAFIS \#2017040311573635) and performed by certified scientists to work with living animals. All efforts were made to minimize animal suffering and to reduce the number of animals used.

\section{Diet}

Following the habituation period, animals were divided into two groups: a control group $(n=23)$ exposed to a standard chow diet (4RF21, $3.952 \mathrm{kcal} / \mathrm{g}$ containing $19.42 \%$ proteins, $2.58 \%$ lipids, $5.54 \%$ fibers, $6.76 \%$ ash, $54.61 \%$ nitrogen-free extract, Mucedola, Italy) and a free-choice high-fat highsugar group (fcHFHS, $n=25$ ) exposed to standard chow with normal tap water, combined with availability of saturated fat ("blanc de boeuf", Vandermoortele, France) and a bottle of $10 \%$ sugar dissolved in water (Powder Sugar, Erstein, France), as previously described [28]. The regimen lasted 6 weeks (Fig. 1a). The sucrose concentration was chosen to be comparable to most sweetened beverages consumed by humans, and as a preferred sugar concentration in rats [31]. Animals were weighed once per week and daily food and liquid intake were recorded every $24 \mathrm{~h}$. Group randomization was established based on the initial animal weight. Total calorie intake was then calculated per day for each rat.

\section{Sample collection and quantitative polymerase chain reaction (qPCR)}

Animals were given an overdose of pentobarbital (182 mg/ rat, i.p.). Weight and body length were recorded to calculate body mass index (BMI, distance tip of nose-anus ${ }^{2} /$ body mass). Individual mesenteric, epididymal, subcutaneous (inguinal), and perirenal white adipose tissues were dissected from the left side, cleaned and weighed. Fresh brains were collected, cut in 1-mm slices in a rat brain matrix, and regions were collected bilaterally (except for the Arc) according to a rat brain stereotaxic atlas [32]. PFC (3 mm punch, 4.68 to $2.5 \mathrm{~mm}$ from bregma, 2 slices), NAc (1.9 mm punch, 3 to $0.6 \mathrm{~mm}$ from bregma, 2 slices), VTA ( $1 \mathrm{~mm}$ punch, -5 to $-6 \mathrm{~mm}$ from bregma, bilateral, 1 slice), and Arc $(1.9 \mathrm{~mm}$ punch, -2.04 to $-3.6 \mathrm{~mm}$ from bregma, central, 1 slice) samples were kept at $-80{ }^{\circ} \mathrm{C}$. Gene expression was analyzed using qPCR as described previously [33]. Briefly, qPCR was run in triplicate using Sso Advanced ${ }^{\mathrm{TM}}$ Universal SYBR Green supermix in a CFX96 Touch $^{\mathrm{TM}}$ apparatus (Biorad) with following thermal cycling parameters: $30 \mathrm{~s}$ at $95^{\circ} \mathrm{C}$ followed by 40 amplification cycles of $5 \mathrm{~s}$ at $95^{\circ}$ and $45 \mathrm{~s}$ at $60^{\circ} \mathrm{C}$. Primer sequences were established using primer3 software (see Supplemental Table 1). Expression levels were normalized to RplpO housekeeping gene levels, commonly used in brain or food-related studies [34, 35 ] and compared between controls and fcHFHS samples using the $2-\Delta \Delta \mathrm{Ct}$ method [36].

\section{Mass spectrometry}

PFC and NAc samples, distinct from the qPCR experiment were prepared as previously described [33]. Briefly, they were sonicated ( 2 times $5 \mathrm{~s}, 90 \mathrm{~W}$ ) in $200 \mu \mathrm{l}$ of $\mathrm{H}_{2} \mathrm{O}$. The homogenate was centrifuged $\left(20,000 \mathrm{~g}, 30 \mathrm{~min}, 4^{\circ} \mathrm{C}\right)$ and supernatant $(150 \mu \mathrm{l})$ was mixed with $50 \mu \mathrm{l}$ of acetonitrile (ACN) $100 \%$ containing $400.26 \mathrm{pmol}$ of D8-2AG (sc480539; Santa Cruz, Heidelberg, Germany) and 100.15 pmol of D4-AEA (Tocris/Biotechne, Lille, France). Samples were centrifuged $\left(20,000 \mathrm{~g}\right.$ for $\left.30 \mathrm{~min}, 4^{\circ} \mathrm{C}\right)$, the supernatant was collected and evaporated to dryness. Samples were re-suspended in $20 \mu \mathrm{l}$ of $\mathrm{ACN} 30 \% / \mathrm{H}_{2} \mathrm{O} 69.9 \% /$ formic acid $0.1 \%$ $(\mathrm{v} / \mathrm{v} / \mathrm{v})$. We did not have enough material to perform the same analysis on individual VTA or Arc samples. Analyses were performed on a Dionex Ultimate 3000 HPLC system coupled with a triple quadrupole Endura mass spectrometer (Thermo Scientific, San Jose, USA), controlled by Xcalibur 

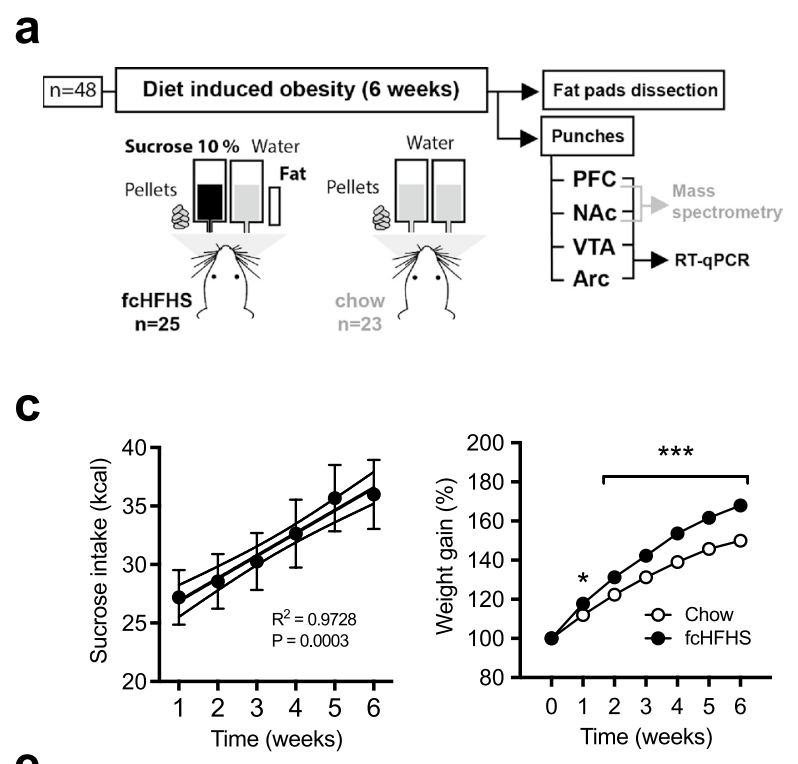

e
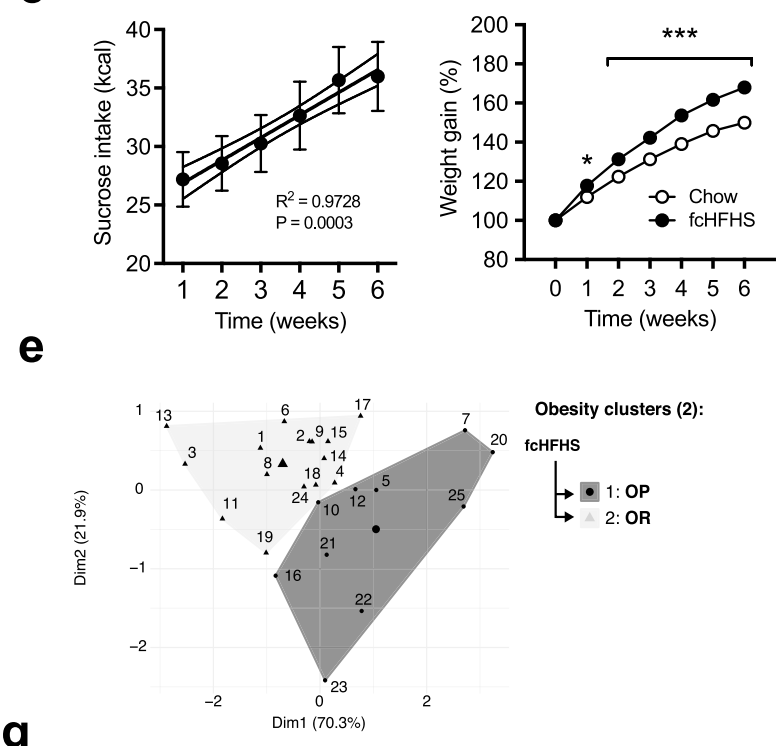

g

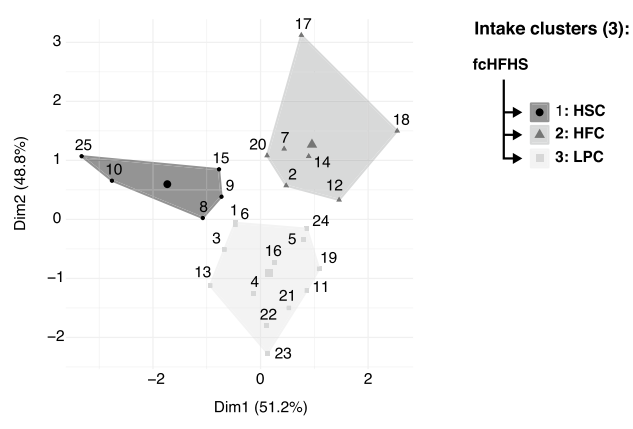

v. 2.0 software (Thermo Electron, San Jose, USA). Samples ( $3 \mu \mathrm{l})$ were loaded onto the column heated at $40^{\circ} \mathrm{C}$. Elution was performed by applying a gradient of mobile phases $\mathrm{A} / \mathrm{B}$ (flow rate of $50 \mu \mathrm{l} / \mathrm{min}$ ). Column, mobile phases, gradient, and MS parameters are detailed in Supplemental Table 2. Qualification and quantification were performed with the multiple reaction monitoring mode (MRM) and based on precursor ion, selective fragment ions and retention times obtained for 2-AG, AEA, D8-2-AG, and D5-AEA. All amounts of endocannabinoids fit within the standard curve limits, with typical analytical ranges from 1fmol-100 pmol to $150 \mathrm{fmol}-100 \mathrm{pmol}$. Precision (CV\% between repeated

h

J b
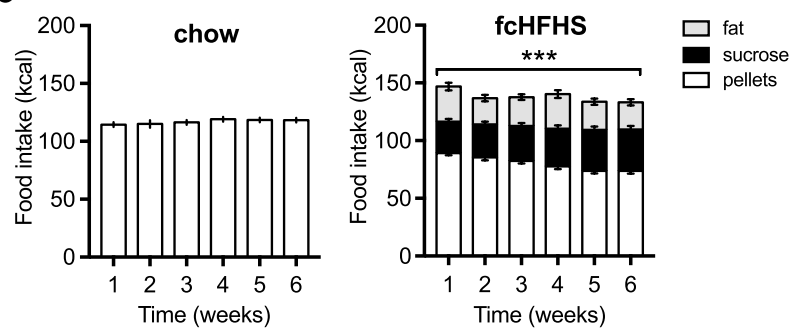

d
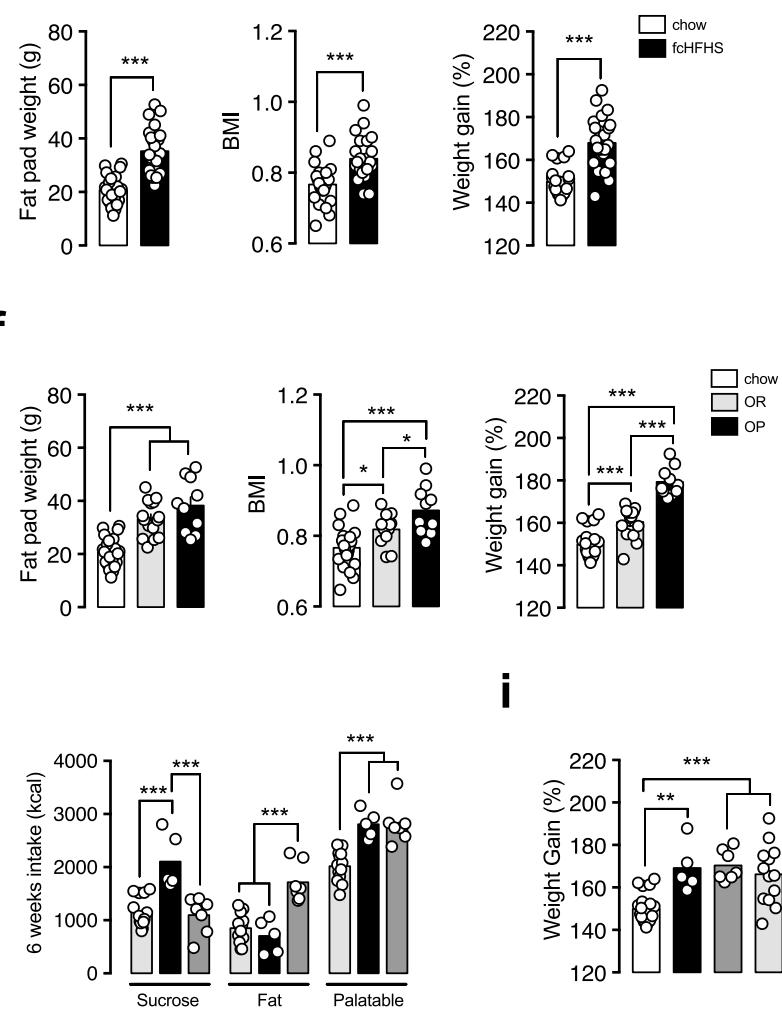

\section{i}

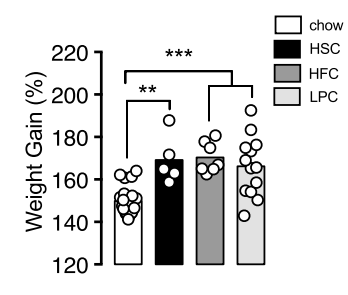

injections of the same sample) values were $<1 \%$ for sameday measurements and $<5 \%$ for inter-day measurements.

\section{Statistical analysis}

k-means clustering and correlograms were performed using R software (https://www.datanovia.com/en/lesso $\mathrm{ns} / \mathrm{k}$-means-clustering-in-r-algorith-and-practical-examp les/). Obesity clusters ( $\mathrm{k}=2$; obesity prone, OP and obesity resistant, OR) were generated using fat pad weight, body mass index, and total weight gain as the 3 variables. Palatable food consumption-based clusters $(k=3$; low palatable 
४Fig. 1 Effects of a 6-week free choice high fat high sugar (fcHFHS) diet on hyperphagia and obesity. a Experimental design. b Mean daily caloric intake in fcHFHS versus control (chow) animals. Caloric intake was significantly higher in the fcHFHS group compared to the chow group over the 6 weeks of the diet. c left panel. Linear regression between mean daily sucrose consumption and time $(n=25)$. Dashed lines represent the $95 \%$ confidence bands of the best-fit line. Sucrose consumption progressively increased over weeks in both groups. Right panel. Mean weekly weight gain during the diet (\% of the body weight at the start of the diet). The fcHFHS diet led to a significant, rapid, and higher increase in weight gain in rats compared to the chow-control animals. d Mean fat pads weight, BMI, and weight gain at the end of the 6-week regimen. These three obesity hallmarks were increased following the diet. e Graphical representation of OP and OR clusters resulting from Km Clustering based on the 3 obesity criteria mean values measured at the end of the experiment (Fat pad weight, BMI and weight gain). $\mathrm{X}$ and $\mathrm{y}$ axes represent the first two components of the principal component analysis after dimensional reduction (3 to 2 variables). $\%=$ percentage of variance. f Comparison of the 3 obesity criteria between groups. BMI and weight gain were significantly higher in OP than OR rats. The 3 obesity criteria were increased in the 2 clusters when compared with the chow group. g Graphical representation of HSC, HFC, and LPC clusters resulting from $\mathrm{Km}$ Clustering based on the 3 palatable food intake-based criteria mean values measured at the end of the experiment (total sucrose intake, total fat intake, and total palatable food intake). Minor geometric forms represent individual values, major geometric forms represent cluster centroids. h Comparison of palatable food intake between clusters. HSC consumed more sucrose, HFC more fat, and LPC less palatable food than animals belonging to the other clusters. i Comparison of weight gain between the chow group and the 3 palatable food intake-based clusters. Weight gain was increased in the 3 clusters compared to the chow group. $\mathbf{j}$ Proportion of OP/OR rats belonging to the 3 palatable intake-based clusters. The same proportions of OP and OR animals were observed in the 3 clusters. In bar graphs, white dots represent individual data. $* p<.005 ; * * p<.001$; $* * * p<.0001, n=5-23$ per group. fcHFHS $(n=25)$; OP obesity prone $(n=10)$; OR obesity resistant $(n=15) ; B M I$ body mass index; $L P C$ low palatable consumers $(n=13) ; H S C$ high sucrose consumers $(n=5) ; H F C$ high fat consumers $(n=7)$

consumers, LPC, high sucrose consumers, HSC and high fat consumers, HFC) were generated using total palatable food, total sucrose, and total fat consumption as the 3 variables. Because the data contained more than 2 variables, scatter plot visualization was performed by applying a dimensionality reduction algorithm (PCA) that outputs two new variables from the three original variables. All qPCR data were analyzed throughout obesity hallmarks and palatable food intake-based subgroups, with the main limitation being a low number of animals in some subgroups. Only statistically significant results are reported.

All data were tested for normality and homoscedasticity before applying parametric statistical tests. Statistical analysis for body weight gain, food consumption, qPCR, and mass spectrometry results were performed using Graphpad Prism 6.0 software. Differences between control and fcHFHS groups were assessed using unpaired two-tailed $t$-tests, and by one-way ANOVA with Tukey's post hoc test for multiple comparisons to assess differences between more than two groups (cluster comparisons). Repeated measures two-way ANOVA and multiple comparison tests including Sidak correction were used to assess differences in food intake and body weight changes over time between groups. Correlation and linear regressions were performed to compare sucrose/ fat intake with time, CB2, and GPR55 relative expression between them and in relation to sucrose consumption.

\section{Results}

\section{Feeding behavior and body composition}

Over the 6-week diet, the fcHFHS group consumed significantly more total calories than the control group, showing a persistent hyperphagia (Fig. 1b; $\mathrm{F}(1,46)=38.72, p<0.0001$, $p<0.006$ for each time point). In the fcHFHS group, whereas calorie intake from fat was stable over weeks (Supplemental Fig. 1a), calorie intake from sucrose progressively increased (Fig. 1c left; $\mathrm{Y}=1.936 * \mathrm{x}+24.94, \mathrm{R}^{2}=0.973, p=0.0005$ ) and conversely, calorie intake from standard chow progressively decreased (Supplemental Fig. 1b; Y $=-3362 *$ $\left.\mathrm{X}+92.14, \mathrm{R}^{2}=0.965 p=0.0005\right)$. Calories consumed from fat or sucrose solution did not significantly differ, although standard chow provided higher calories than palatable food (Fig. 1b; F $(1,48)=50.85, p<0.0001, p<0.0007$ for each time point). Hyperphagia of the fcHFHS group resulted in a rapid increase in weight gain compared to the control group, and was significantly different, already following the first week of the diet (Fig. 1c, d; F(1, 46) =44.12, $p<0.0001$, $p=0.027$ for the first week, $p<0.0001$ for other time points). Diet exposure also increased abdominal fat pads, weight gain and BMI, two other obesity hallmarks (Fig. 1d; $p<0.0001$ for each obesity hallmark).

\section{K-means clustering analysis}

Besides data analysis of control and fcHFHS groups, we also generated statistical analysis using a k-mean clusters to highlight distinct populations inside the obesogenic group, without a prior assumption (see methods). Using three obesity hallmarks (fat pad weight, BMI, and weight gain) as variables to generate "obesity clusters", the fcHFHS group was divided into two subgroups: obesity prone (OP; $n=10$ ) and obesity resistant (OR; $n=15$ ) animals (Fig. 1e). There were no differences in weight between OP, OR, and controls before the regimen (see Supplemental Fig. 2b). Both OP and OR groups showed increased fat pad weight $(\mathrm{F}(2$, $45)=27.55, p<0.0001$; chow vs OR and chow vs OP: $p s<0.0001)$, BMI $(\mathrm{F}(2,45)=14.23, p<0.0001$, chow vs OR: $p=0.014$, chow vs OP: $p<0.0001)$ and weight gain $(\mathrm{F}(2,45)=65.39, p<0.0001$, chow vs OR and chow vs OP: $p s<0.0001)$ compared to the control group (Fig. 1f). 
Although fat pad weight at the end of the diet did not differ between OR and OP groups, BMI and weight gain were significantly increased in the OP group (BMI: $p=0.048$; weight gain: $p<0.0001$ ). The analysis of chow intake over the 6-week regimen revealed that the OP group consumed more chow than the OR group $(p=0.016$, Supplemental Fig. 2a).

In a parallel cluster analysis, total sucrose intake, total fat intake, and total palatable food intake over the 6 week-diet were used as variables and generated 3 "palatable food clusters" subgroups: high-sucrose consumers (HSC; $n=5$ ), highfat consumers (HFC; $n=7$ ) and low palatable food consumers (LPC; $\mathrm{n}=13$ ) (Fig. 1g). HSC, HFC, and LPC consumed, respectively, more sucrose $(\mathrm{F}(2,22)=14.78, p<0.0001$, HSC vs LPC: $p=0.0001$, HSC vs HFC: $p=0.0002$ ), more fat $(\mathrm{F}(2,22)=22,43, p<0.0001$, HFC vs LPC: $p<0.0001$, HFC vs HSC: $p<0.0001)$, and less palatable food $(\mathrm{F}(2$, $22)=20.67, p<0.0001$, LPC vs HSC: $p=0.0002$, LPC vs HFC: $p<0.0001)$ than the two other groups for each comparison (Fig. 1h). Total chow intake was not significantly different across groups (Supplemental Fig. 2c). Importantly, weight gain at the end of the diet was increased compared to the control group $[\mathrm{F}(3,44)=14.18, p<0.0001$; HFC vs LPC: $p<0.0001$, HSC vs chow: $p=0.0012$, HFC vs chow: $p<0.0001$, LPC vs chow: $p<0.0001$ ], but did not differ across these three subgroups (Fig. 1i), neither before the regimen (Supplemental Fig. 2d). The proportion of OP and OR rats was similar in HSC, HFC, and LPC groups, indicating that obesity and palatable food clusters were independent (Fig. 1j).

\section{Dopamine gene expression and dopamine levels}

We first investigated the effects of a fcHFHS diet on the expression of genes from the DA system. Catechol-O-methyl transferase (degradation enzyme for DA, COMT) mRNA was increased in the PFC (Fig. 2a; $p=0.024$ ) and NAc (Fig. $2 b, p=0.012$ ) following the diet. Interestingly, and as previously shown by others using a clustering approach in a diet-induced obesity model [37], separation of the fcHFHS group into OP/OR subgroups revealed a decrease in DA D1 receptor transcripts in the OP group compared to the control group $(\mathrm{F}(2,34)=3.939, p=0.029)$, although no difference was observed between control and OR groups (Fig. 2c). DA contents in the NAc, obtained using mass spectrometry, were no different between fcHFHS and control groups (Fig. 2d). In the VTA, the fcHFHS diet induced an increase in D1 receptor transcripts $(p=0.0067)$ and a decrease in D2 receptor $(p=0.0042)$, DAT $(p<0.001)$, and TH $(p<0.001)$ synthesis enzyme transcripts (Fig. 2e). No significant differences were detected following the cluster analysis in OP and OR samples, or with the palatable food clusters (data not shown).

\section{Cannabinoid gene expression and endocannabinoid levels}

We first investigated the effects of a fcHFHS diet on gene expression from the endocannabinoid system in the NAc. Transcripts coding for an AEA synthesis enzyme, NAPEPLD, and AEA degradation enzyme, FAAH, were, respectively, increased $(p=0.030)$ and decreased $(p=0.034)$ in the NAc of the fcHFHS group compared to the control group (Fig. 3a, left graph). Both transcripts coding for a 2-AG synthesis enzyme, DAGL, and degradation enzyme, MGL, were decreased following fcHFHS diet exposure (Fig. 3a, left graph; DAGL: $p=0.013$, MGL: $p=0.022$ ). The cannabinoid receptors CB1, CB2, and GPR55 showed distinct regulation patterns in the NAc. CB1 transcripts were not regulated, whereas levels of CB2 and GPR55 receptor transcripts showed a strong variability in the fcHFHS group (Fig. 3a, left graph). The palatable food-clustering explained this variability with an increase in $\mathrm{CB} 2$ and GPR55 transcripts in the HSC compared to control, HF, and LPC groups (Fig. 3b; CB2: $[\mathrm{F}(3,25)=12.45, p<0.0001$, HSC vs chow: $p=0.0037$, HSC vs HFC: $p=0.0003$, HSC vs LPC: $p<0.0001]$; GPR55: $[\mathrm{F}(3,25)=9.716, p=0.0002$, HSC vs chow: $p=0.0008$, HSC vs HFC: $p=0.001$, HSC vs LPC: $p<0.0003$ ]. Interestingly, we observed a trend for an opposite regulation with a decrease in CB2 and GPR55 transcripts in HFC and LPC groups. A strong correlation between the CB2 and GPR55 receptor transcript levels was observed (Fig. 3c, left graph; $\mathrm{R}^{2}=0.916, p<0.0001$ ). Importantly, this correlation was found in all animals, including the control group. Interestingly, CB2 and GPR55 transcript levels were correlated with total sucrose intake at the end of the fcHFHS diet (Fig. 3c, right graph; $\mathrm{R}^{2}=0.39, p=0.0127$; Supplemental Fig. 1c; $\left.\mathrm{R}^{2}=0.38, p=0.015\right)$. No significant correlations were observed for CB2 or GPR55 and fat mass (Supplemental Fig. 1d). In the NAc, mass spectrometry measurements revealed a decrease in 2-AG levels in the fcHFHS group compared to the control group (Fig. 3a, right graph; $p=0.0004$ ) whereas no difference was observed for AEA (Fig. 3a, middle graph). In the VTA, CB1 and CB2 receptor transcript levels were oppositely regulated following the fcHFHS diet with a decrease and an increase, respectively, in this group compared to the control group (Fig. 3d; CB1: $p=0.012$, CB2: $p=0.002)$. Moreover, fcHFHS diet exposure induced a global decrease in transcripts for AEA and 2-AG synthesis and degradation enzymes (Fig. 3d; NAPE: $p=0.0002$, FAAH, DAGL and MGL: $p s<0.0001$ ). Finally, in the Arc, GPR55 transcripts were decreased in the fcHFHS group compared to the control group (Fig. 3e; $p=0.0009)$. The variability observed for levels of CB1 transcripts in the fcHFHS group (Fig. 3e) could be explained by a decrease in the OP compared to the OR subgroup [Fig. 3f; $\mathrm{F}(2,23)=4.95, p=0.016$, OP vs OR: $p=0.013$ ]. 
a

PFC

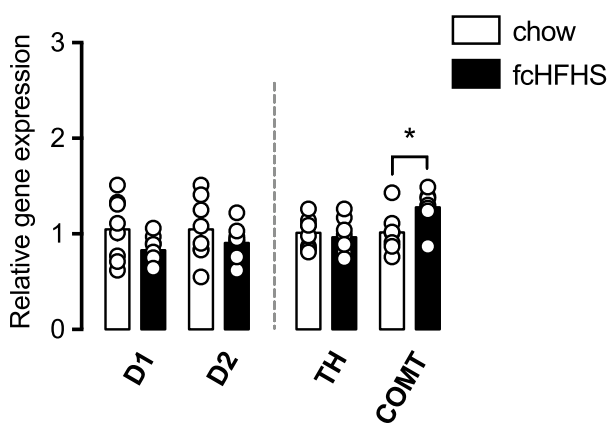

C

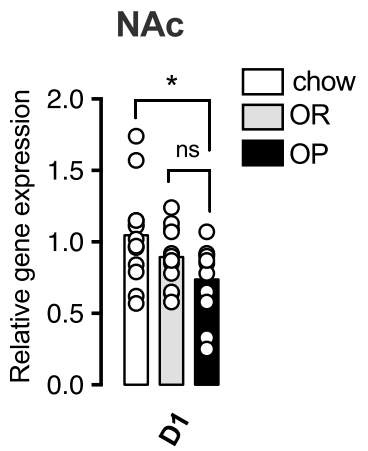

d

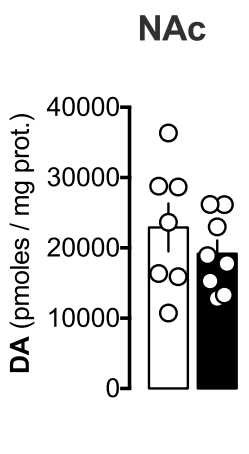

Fig. 2 Effects of fcHFHS on dopamine related gene expression in the reward system and dopamine content in the NAc. a In the PFC, COMT transcripts were increased following the diet. b In the NAc, COMT transcripts were increased in the fcHFHS group compared to the chow group and D1 receptor transcripts were decreased in the OP group compared to the chow group. c Dopamine levels in the NAc did not differ between chow and fcHFHS groups. $\mathbf{d}$ In the VTA, fcHFHS oppositely regulated D1 and D2 receptor transcripts (increase

No regulation of cannabinoid gene expression or endocannabinoid levels was detected in the PFC in our conditions (Supplemental Fig. 3 a,b).

\section{Gene expression regulation in the homeostatic system}

We also investigated the effects of a fcHFHS diet on gene expression from the homeostatic system in the VTA and Arc. In the VTA, diet exposure decreased the expression of POMC anorexigenic peptide (Fig. 4a; POMC: $p=0.029$ ). In the Arc, transcripts for the growth hormone secretagogue receptor or ghrelin receptor (GR) were significantly decreased in the fcHFHS group compared to the control group (Fig. 4b, left; $p=0.026$ ). Separation of the fcHFHS group into OP/OR subgroups using the obesity hallmarksclustering revealed a significant increase in NPY transcripts in the OP group compared to the OR and control groups
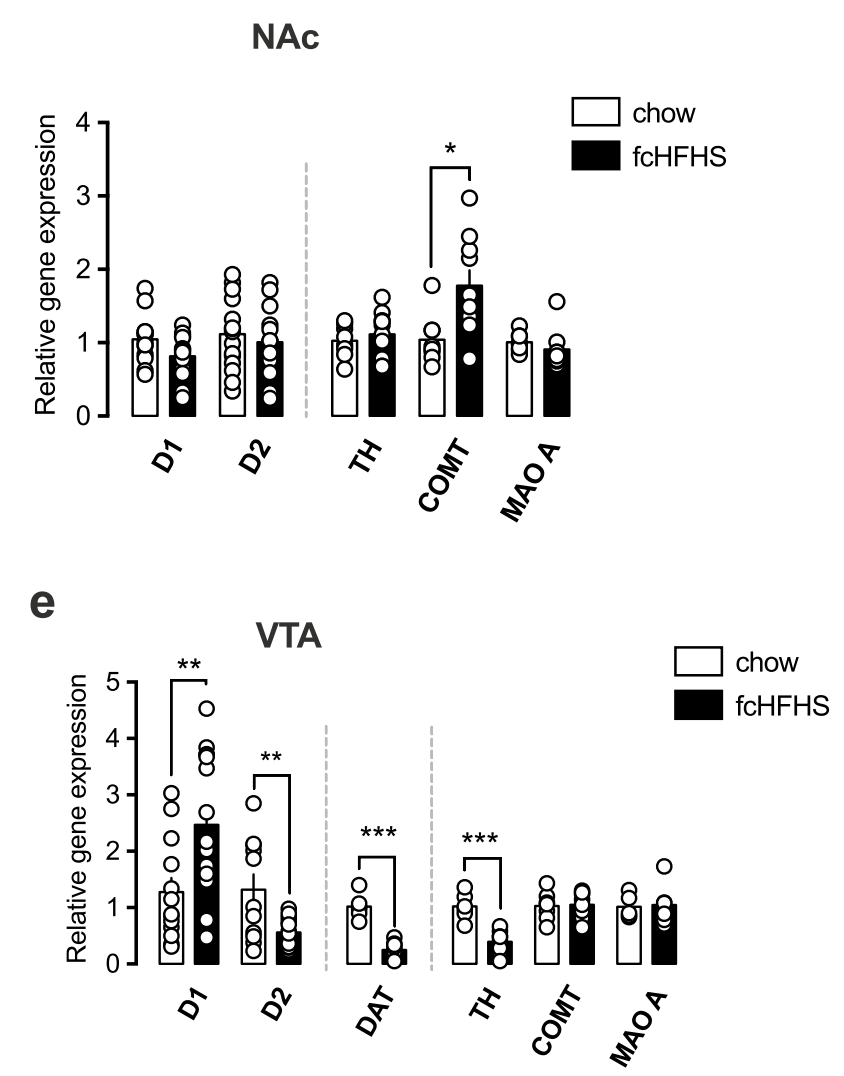

and decrease, respectively). Both DAT and TH transcripts were decreased in the fcHFHS group compared to the chow group. (White dots represent individual data. $* p<.005 ; * * p<.001 ; * * * p<.0001$, $n=5-15$ per group. COMT Catechol O-methyltransferase; D1 Dopamine receptor D1; D2 Dopamine receptor D2; DAT Dopamine transporter; $M A O A$ Monoamine oxidase A; $T H$ tyrosine hydroxylase; $N A c$ nucleus accumbens; VTA ventral tegmental area; $f c H F H S$ free choice high fat high sugar

(Fig. 4c, right; $\mathrm{F}(2,21)=4.66, p=0.021$; OP vs chow: $p=0.034$, OP vs OR: $p=0.038$ ).

\section{Discussion}

Here we provide a detailed summary (Fig. 5) of endocannabinoid system modulation by a fcHFHS diet, with cluster analysis revealing increases in both CB2 and GPCR55 in the NAc of the HSC. As well we observed a decrease in CB1 transcripts in the Arc of OP animals and an increase in the same measure for OR subgroups. High sugar intake induced an increase in both CB2 and GPR55 transcripts in the NAc, levels that were correlated with each other and with total sucrose intake following the 6-week diet. Interestingly, a saturated fat diet can induce inflammatory processes in the mouse NAc, an effect that mediated anxio-depressive behavior and compulsive 

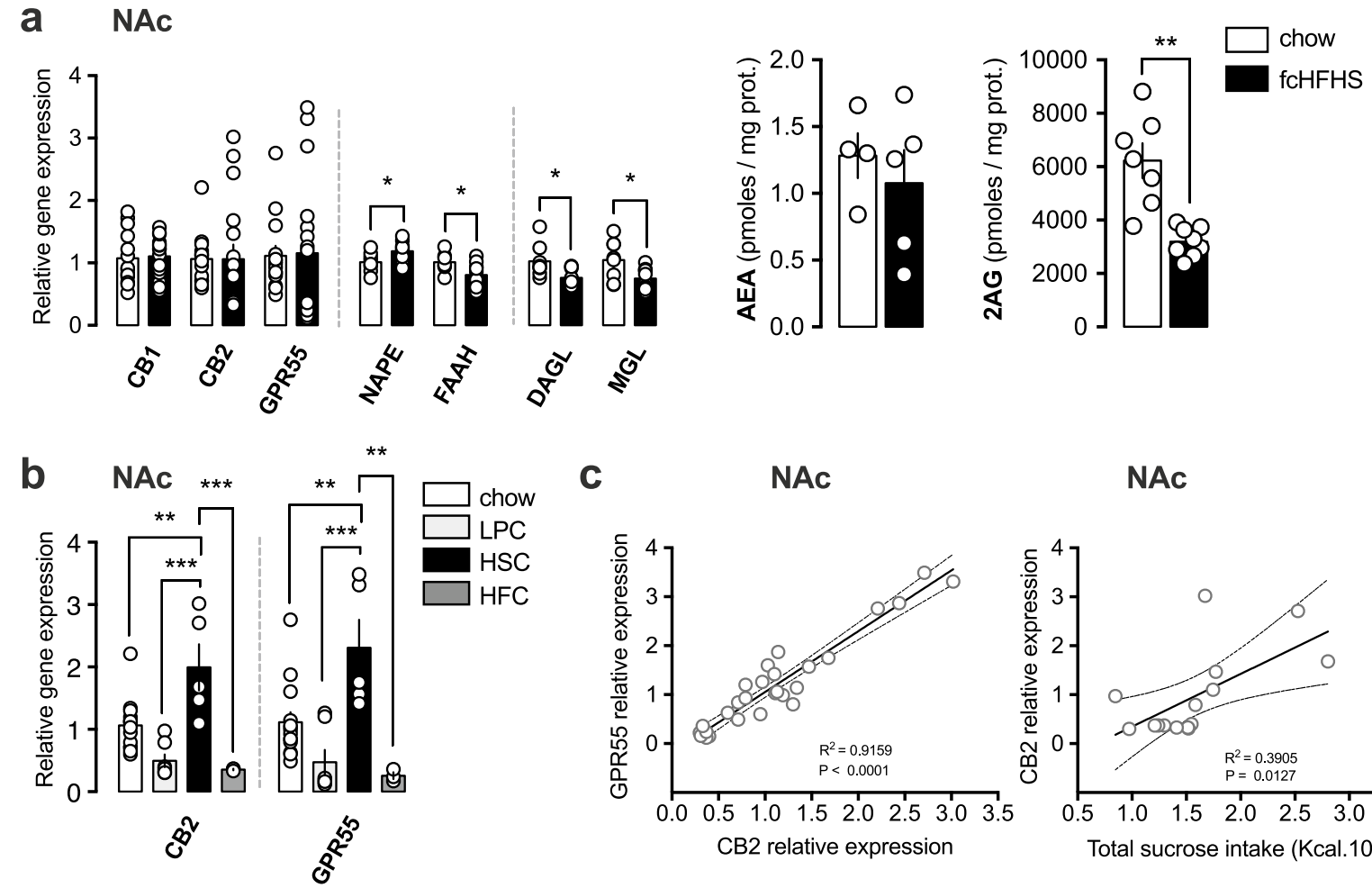

C

NAC

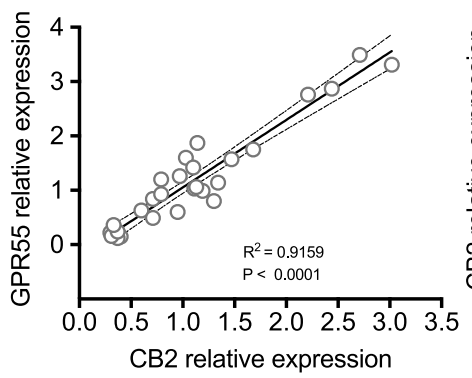

CB2 relative expression

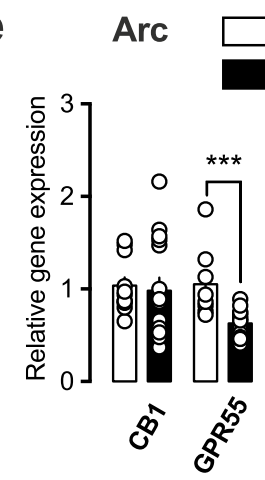
fcHFHS
NAc

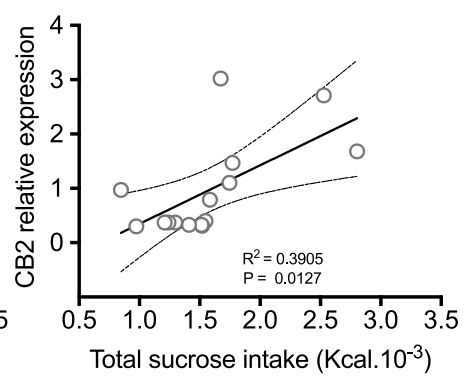

f

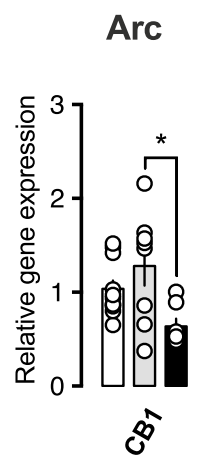

Fig. 3 Effects of fcHFHS on endocannabinoid system-related gene expression and endocannabinoid levels in the PFC and the NAc. a In the NAc, fcHFHS increased NAPE transcripts and decreased FAAH, DAGL, and MGL transcripts and 2-AG levels. b In the NAc, palatable food intake-based $\mathrm{Km}$ clustering explained the variability observed for CB2 and GPR55 transcripts by revealing an increase in the HSC group. c GPR55 and CB2 transcript levels were correlated in animals from the two groups (graph on the left). CB2 gene expression was also correlated with total sucrose intake consumed throughout the experiment. d In the VTA, transcripts for CB1 and endocannabinoid synthesis and degradation enzymes were decreased in the fcHFHS group compared to the chow group. In contrast, fcHFHS was responsible for increased $\mathrm{CB} 2$ transcripts. e In the arcuate nucleus,
GPR55 transcripts were decreased in the fcHFHS group compared to the chow group. f Obesity hallmark-based $\mathrm{Km}$ clustering revealed a decrease in CB1 transcripts in the OP cluster compared to the OR cluster. White dots represent individual data. * $p<.005 ; * * p<.001$; $* * * \quad p<.0001, n=3-16$ per group. 2-AG 2-Arachidonoyl glycerol; $A E A$ Anandamide; $C B 1$ Cannabinoid receptor type 1, CB2 Cannabinoid receptor type 2; GPR55 G protein-coupled receptor 55; DAGL Diacylglycerol lipase; FAAH Fatty acid amide hydrolase; $M G L$ Monoacylglycerol lipase; NAPE N-acyl phosphatidylethanolamine phospholipase D; HFC High Fat Consumers; HSC High Sucrose Consumers; $L P C$ Low Palatable Consumers; $O P$ Obesity Prone; $O R$ Obesity Resistant; NAc nucleus accumbens; Arc Arcuate nucleus VTA ventral tegmental area; $f c H F H S$ free choice high fat high sugar sucrose seeking [38]. CB2 receptors participate in the regulation of cytokine release and immune cell function [39], and both CB2 and GPR55 receptors are expressed in microglia. Up-regulation of their transcripts may underline NAc inflammatory responses following diet exposure; based on similar findings with high-fat diet in mice 

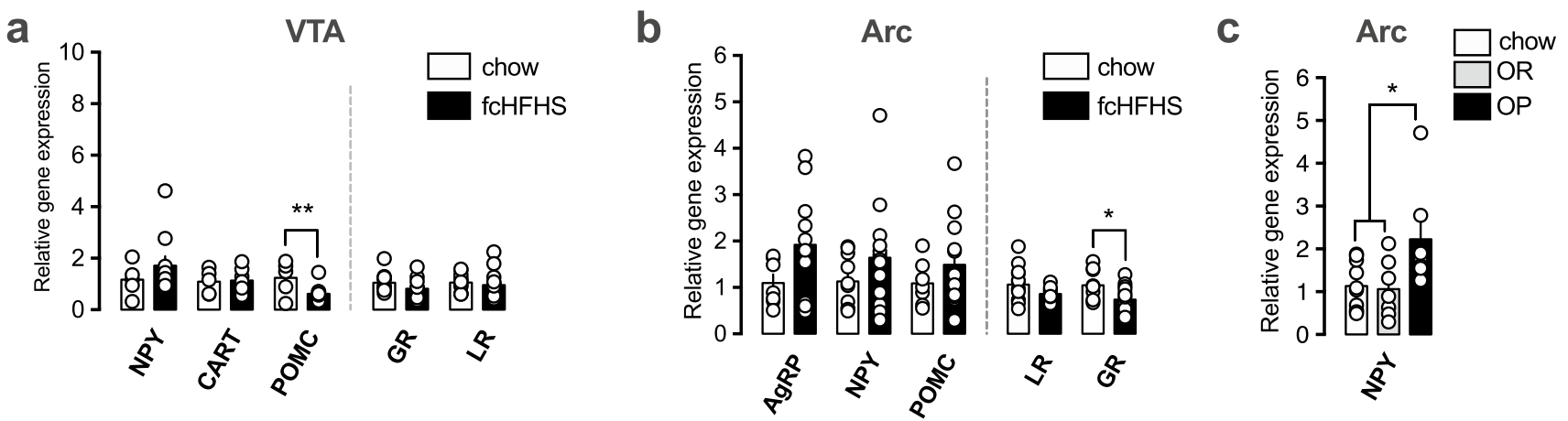

Fig. 4 Effects of fcHFHS on homeostatic system-related gene expression in the reward system and the Arc. a In the VTA, POMC was decreased in the fcHFHS group compared to the chow group. b In the Arc, GR transcripts were decreased in the OP group compared to the chow group. c Obesity hallmark-based $\mathrm{Km}$ clustering explained the variability observed for NPY transcripts by revealing an increase in the OP cluster. White dots represent individual data. ${ }^{*} p<.005$;

\section{a}

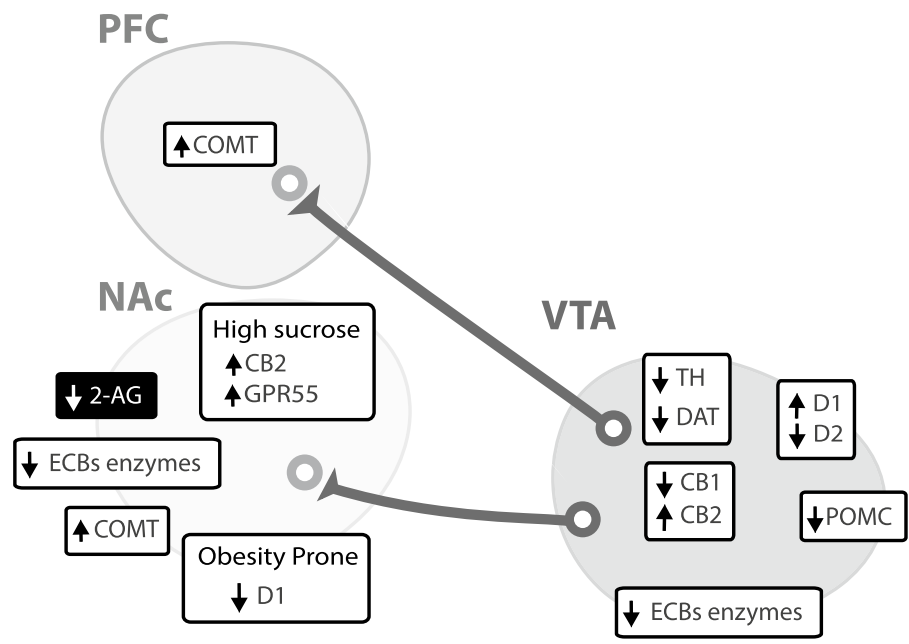

** $p<.001 ; * * * p<.0001, n=5-14$ per group. AgRP Agouti-related peptide; CART Cocaine and amphetamine regulated transcript; $G R$ Growth hormone secretagogue receptor; $L R$ Leptin receptor; $N P Y$ Neuropeptide Y; $O P$ Obesity Prone; $O R$ Obesity Resistant; $P O M C$ Proopiomelanocortin; Arc arcuate nucleus; VTA ventral tegmental area; $f c H F H S$ free choice high fat high sugar b

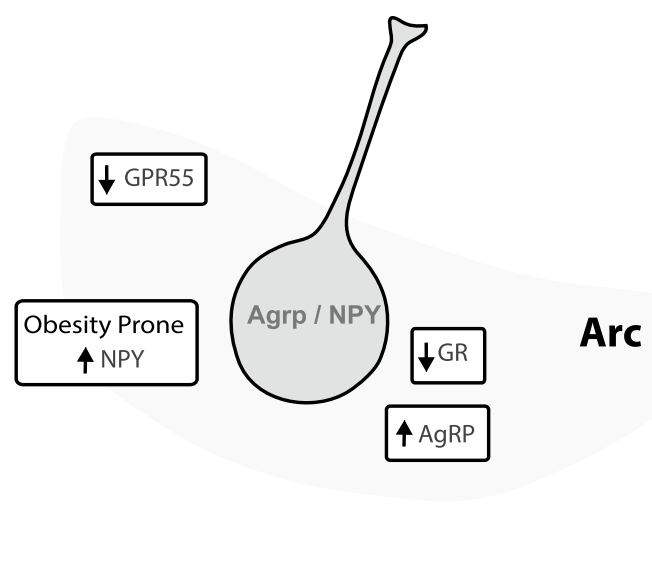

Fig. 5 Schematic summary of results. a Endocannabinoid levels and dopamine, endocannabinoid and homeostatic systems-related gene expression changes in the mesocorticolimbic system following the 6-week fcHFHS diet. b Regulation of endocannabinoid or homeo-

[38], we hypothesize that these changes could increase excessive sucrose intake, although mechanisms underlying such adaptations are still unknown. CB2 receptors are also expressed on neurons and could, therefore, play a role on the rewarding effects of palatable food through distinct mechanisms. Less is known about the potential role of GPR55 in eating disorders, but a functional polymorphism in its gene may be a risk factor for anorexia nervosa [40] and this receptor has been proposed as a new pharmaceutical target to treat obesity and type 2 diabetes [41]. In static system-related gene expression in the Arc following the $\mathrm{fcH}$ FHS diet. $D A$ dopamine; $E C B$ endocannabinoid; $A r c$ arcuate nucleus; $N A c$ nucleus accumbens; $P F C$ prefrontal cortex; VTA ventral tegmental area

addition, direct interaction between CB2 and GPR55 in cancer cells could participate in modulation of receptor signaling $[42,43]$; similar signaling modulation of these two receptors as heterodimers may contribute to feeding behavior. In addition, other heterodimerization of receptors may participate in the adaptations observed in the control of palatable food intake, as CB1 receptors have been shown to form heteromers with NAc opioid receptors $[44,45]$ which mediate the hedonic aspects of sweet foods [46]. Further examination of such molecular adaptations 
would bring insights into the mechanisms mediating biological changes associated with palatable food intake.

We observed a decrease in 2-AG levels in the NAc of fcHFHS rats, consistent with the local decrease in DAGL and MGL transcripts. Decreased 2-AG levels have been reported in the limbic forebrain during food consumption [21]. Injections of endocannabinoids in the NAc induced hyperphagia, an effect reversed by CB1 receptor antagonism [21, 47]. Genetically modified mice with reduced 2-AG levels in the forebrain showed a decreased fat preference [48]. Moreover, systemic injections of CB1R antagonists decreased palatable food-evoked local DA release [18]. Altogether, this suggests that the decrease in 2-AG levels following the 6-week diet could reflect an endocannabinoid-mediated compensatory mechanism that functions to decrease palatable food-induced hyperphagia and restore "homeostatic" feeding.

In the VTA, we observed an opposite regulation of CB1 (decrease) and CB2 (increase) receptor transcripts in fcHFHS rats, whereas mRNA coding for the synthesis and degradation enzymes for both endocannabinoids were decreased following the diet. CB1 receptors are expressed, primarily, in afferent terminals (excitatory or inhibitory) where they contribute to short- and long-term endocannabinoid-mediated synaptic plasticity [16]. Activation of CB1 receptors on axon terminals of GABAergic neurons in the VTA inhibits GABA transmission, leading to an increase in the firing pattern of DA neurons [49]. In this context, cocaine-induced DA release in the NAc is partially due to an endocannabinoidmediated disinhibitory mechanism of VTA DA neurons [50]. Based on similitudes observed between drugs of abuse and excessive food intake [11], we hypothesize that a similar mechanism could arise for food-induced DA release with reduced DA neuronal activity in the VTA. Increases in AEA and 2-AG tone enhance DA transmission in the NAc through CB1 receptors $[19,51]$ and 2-AG is synthetized in the VTA after cocaine exposure to suppress GABAergic inhibition of VTA DA neurons [50]. A global decrease in endocannabinoids in the VTA following the diet would be consistent with a reduced activity of VTA DA neurons. Altogether, regulation of endocannabinoid-related transcripts in the VTA following the fcHFHS diet could contribute to a DA deficiency syndrome of obesity or reflect a compensatory mechanism to decrease the hedonic value of palatable food and this remains to be investigated at the protein level.

In the Arc, the fcHFHS diet induced a decrease of GPR55 transcripts, in both OP and OR rats, suggesting a compensatory mechanism to reduce hyperphagia by limiting activity of AgRP/NPY neurons. However, little is known about the role of GPR55 at central synapses. Interestingly, CB1 receptor transcripts were decreased in OP compared to OR rats. A recent neuroanatomical study in mice showed that CB1 receptors are expressed by GABA terminals contacting AgRP/NPY neurons in the Arc [52]. Thus, if the regulated transcripts reflect a similar regulated level of protein, a decrease in $\mathrm{CB} 1$ receptor expression in these GABA terminals of OP rats could reduce the GABAergic tone over AgRP/NPY orexigenic neurons, leading to increased firing and hyperphagia. This will need to be further investigated.

In the present study, we confirmed that long-term exposure to palatable food resulted in prolonged hyperphagia and an obese phenotype, as previously reported [28]. We observed increased COMT transcripts in the PFC and NAc of fcHFHS rats (Fig. 2a,b), which could result in increased protein expression and activity and, therefore, potentially a higher DA degradation at the synaptic cleft, thus reducing local DA levels. It has been shown that COMT activity can modulate DA in the PFC, with a COMT inhibitor enhancing pharmacologically evoked dopamine release in the PFC without affecting catecholamine basal levels [53]. The same inhibitor also enhanced food-evoked dopamine release in the rat PFC [54]. Such effect could be linked to the DA deficiency syndrome and altered reward responsivity observed in obese patients. Nevertheless, given the PFC roles in multiple processes associated with compulsive behaviors (e.g., inhibition, decision making etc.), the contribution of DA in the PFC to palatable food intake likely occurs through multiple mechanisms. Also, in addition to an association between body weight and COMT genetic variants [55], subjects with genetic variants in $D A T$ and $C O M T$ genes displayed altered activity in several reward-related brain regions during reward anticipation and delivery [56]. In line with previous studies using similar diet [37], we observed decreased D1 transcripts in the NAc of OP rats (Fig. 2c), validating the obesity hallmarks-based clustering. In addition, these data and those showing decreased TH in the VTA are consistent with previous reports of increased striatal D1 mRNA in junk-food non-gainers versus junk-food gainers, as well as a decreased TH in the VTA of gainers versus non-gainers [12]. Our results, if correlated with regulation at the protein level, would also be in accordance with decreased D1 receptor protein levels and impaired D1 receptor signaling observed in the NAc of hyperphagic rats, and reduced hedonic food intake following D1 receptor stimulation [57]. In addition, the fcHFHS diet induced an increase of D1, but a decrease in regulation of D2 receptor transcripts, in the VTA. On the other hand, recent studies reported that obesity prone rats exhibit increased DA system sensitivity prior to diet manipulation $[58,59]$. Thus, the question of whether these differences reflect vulnerability factors or are the consequence of the diet itself remains an open question.

The increased NPY expression in the Arc of OP rats provided further validation of molecular changes in dietinduced obesity paradigms [60-63], suggesting an important role of this peptide in the pathogenesis of obesity. This up-regulation could lead OP rats to consume more calories, resulting in weight gain. In our conditions, a 
difference between OP and OR rats in food intake was only observed with standard normocaloric food intake (Supplemental Fig. 2a), suggesting the ability to differentiate feeding driven by homeostatic versus hedonic cues using this clustering approach. These findings, therefore, help to strengthen the fcHFHS paradigm as a reliable preclinical model for human diet-induced obesity and metabolic dysfunction [27]. Indeed, this preclinical model provided rats with the choice between four different food items with distinct fluidity, texture, form, and nutritive content [28]. All experiments included a control group that only had access to regular chow, allowing us to identify behavioural and biological changes specifically associated with a high-fat and high-sugar diet. This model has been used repeatedly in experimental research, effectively producing overeating, body weight gain, and body fat accumulation in both rats and mice [27]. Despite the limitations of translating preclinical findings to human studies, these models have consistently provided data that are useful in developing and testing hypothesis regarding molecular mechanisms underlying weight disorders $[64,65]$. Moreover, and this will be our future goal, analysis of the effects of this fcHFHS diet in females may provide novel insight into endocannabinoid system adaptations following palatable food intake, which may contribute to sex differences in human pathology [66].

\section{Conclusion}

Cluster analysis allowed us to distinguish between rodents that gain different amounts of weight and those that consume excessive amounts of sugar or fat. These distinctions helped to decipher subtle molecular adaptations of the endocannabinoid system that were specific to sugar or fat, weight gain, or excessive intake of sugar. This analysis, therefore, provided insight into cannabinoid mechanisms of action and how these relate to maladaptive feeding. Current cannabinoid treatment strategies for obesity include CB1 antagonists to limit depressive side effects observed with inverse agonists, such as rimonabant, inhibitors of synthesis enzymes to increase endocannabinoids, and peripheral ligands to limit central cannabinoid-mediated psychologic effects (see [16, 67]). Unfortunately, these strategies have limited utility due to side effects or minimal effects on eating. Our results highlighted CB2 as a regulated gene following an obesogenic diet, in link with the level of sugar consumption. Future studies should explore the implications of this receptor at the neuronal and glial levels, examine the effect of selective CB2 compounds to minimize neuronal changes or neuroinflammatory states and propose novel strategies to refine treatments for obesity.
Supplementary Information The online version contains supplementary material available at https://doi.org/10.1007/s00394-021-02613-0.

Acknowledgements This project was supported by the Universite de Strasbourg, the Centre National de la Recherche Scientifique (CNRS), by the Programme International de Cooperation Scientifique (PICS CNRS), and by the Natural Sciences and Engineering Research Council of Canada (NSERC). RB received a postdoctoral fellowship from the Fondation pour la Recherche Médicale (FRM). We thank datanovia. com for data analysis resources. The authors declare no conflict of interest.

Authors contribution $\mathrm{RB}, \mathrm{MCO}, \mathrm{KB}$ conceived the study and wrote the paper. RB, AH, DF, VC, KB performed the experiments. RB, DF, AH, $\mathrm{KB}$ analyzed the data and designed the figures. YG, VC contributed to the design and analysis of the mass spectrometry experiment. JM contributed to the design of the regimen and the discussion of the data. All authors approved the final version of the manuscript.

Data availability statement All the data supporting the findings of this study can be provided upon request from the corresponding author.

\section{Declarations}

Conflict of interest The authors have no competing financial interests in relation to the work described.

\section{References}

1. Guh DP, Zhang W, Bansback N, Amarsi Z, Birmingham CL, Anis AH (2009) The incidence of co-morbidities related to obesity and overweight: a systematic review and meta-analysis. BMC Public Health 9:88. https://doi.org/10.1186/1471-2458-9-88

2. Clement K, Coupaye M, Laville M, Oppert JM, Ziegler O (2020) COVID-19: a lever for the recognition of obesity as a disease? The french experience. Obesity (Silver Spring) 28:1584-1585. https:// doi.org/10.1002/oby.22924

3. Hill JO, Peters JC (1998) Environmental contributions to the obesity epidemic. Science 280:1371-1374. https://doi.org/10.1126/ science.280.5368.1371

4. Fletcher PC, Kenny PJ (2018) Food addiction: a valid concept? Neuropsychopharmacology 43:2506-2513. https://doi.org/10. 1038/s41386-018-0203-9

5. Ferrario CR, Labouebe G, Liu S, Nieh EH, Routh VH, Xu S et al (2016) Homeostasis meets motivation in the battle to control food intake. J Neurosci 36:11469-11481. https://doi.org/10.1523/ JNEUROSCI.2338-16.2016

6. Morton GJ, Meek TH, Schwartz MW (2014) Neurobiology of food intake in health and disease. Nat Rev Neurosci 15:367-378. https://doi.org/10.1038/nrn3745

7. Geiger BM, Haburcak M, Avena NM, Moyer MC, Hoebel BG, Pothos EN (2009) Deficits of mesolimbic dopamine neurotransmission in rat dietary obesity. Neuroscience 159:1193-1199. https://doi.org/10.1016/j.neuroscience.2009.02.007

8. Hoebel BG, Hernandez L, Schwartz DH, Mark GP, Hunter GA (1989) Microdialysis studies of brain norepinephrine, serotonin, and dopamine release during ingestive behavior. Theoretical and clinical implications. Ann N Y Acad Sci 575:171-191. https://doi. org/10.1111/j.1749-6632.1989.tb53242.x

9. Lutter M, Nestler EJ (2009) Homeostatic and hedonic signals interact in the regulation of food intake. J Nutr 139:629-632. https://doi.org/10.3945/jn.108.097618 
10. Garcia-Garcia I, Jurado MA, Garolera M, Segura B, MarquesIturria I, Pueyo R et al (2013) Functional connectivity in obesity during reward processing. Neuroimage 66:232-239. https://doi. org/10.1016/j.neuroimage.2012.10.035

11. Volkow ND, Wise RA, Baler R (2017) The dopamine motive system: implications for drug and food addiction. Nat Rev Neurosci 18:741-752. https://doi.org/10.1038/nrn.2017.130

12. Robinson MJ, Burghardt PR, Patterson CM, Nobile CW, Akil $\mathrm{H}$, Watson SJ et al (2015) Individual differences in cue-induced motivation and striatal systems in rats susceptible to diet-induced obesity. Neuropsychopharmacology 40:2113-2123. https://doi. org/10.1038/npp.2015.71

13. Small DM (2009) Individual differences in the neurophysiology of reward and the obesity epidemic. Int J Obes (Lond) 33(Suppl 2):S44-S48. https://doi.org/10.1038/ijo.2009.71

14. Johnson PM, Kenny PJ (2010) Dopamine D2 receptors in addiction-like reward dysfunction and compulsive eating in obese rats. Nat Neurosci 13:635-641. https://doi.org/10.1038/nn.2519

15. Vucetic Z, Carlin JL, Totoki K, Reyes TM (2012) Epigenetic dysregulation of the dopamine system in diet-induced obesity. J Neurochem 120:891-898. https://doi.org/10.1111/j.1471-4159. 2012.07649.x

16. Lau BK, Cota D, Cristino L, Borgland SL (2017) Endocannabinoid modulation of homeostatic and non-homeostatic feeding circuits. Neuropharmacology 124:38-51. https://doi.org/10.1016/j. neuropharm.2017.05.033

17. Di Marzo V, Ligresti A, Cristino L (2009) The endocannabinoid system as a link between homoeostatic and hedonic pathways involved in energy balance regulation. Int J Obes (Lond) 33(Suppl 2):S18-24. https://doi.org/10.1038/ijo.2009.67

18. Melis T, Succu S, Sanna F, Boi A, Argiolas A, Melis MR (2007) The cannabinoid antagonist SR 141716A (Rimonabant) reduces the increase of extra-cellular dopamine release in the rat nucleus accumbens induced by a novel high palatable food. Neurosci Lett 419:231-235. https://doi.org/10.1016/j.neulet.2007.04.012

19. Solinas M, Justinova Z, Goldberg SR, Tanda G (2006) Anandamide administration alone and after inhibition of fatty acid amide hydrolase (FAAH) increases dopamine levels in the nucleus accumbens shell in rats. J Neurochem 98:408-419. https://doi. org/10.1111/j.1471-4159.2006.03880.x

20. Mahler SV, Smith KS, Berridge KC (2007) Endocannabinoid hedonic hotspot for sensory pleasure: anandamide in nucleus accumbens shell enhances "liking" of a sweet reward. Neuropsychopharmacology 32:2267-2278. https://doi.org/10.1038/sj.npp. 1301376

21. Kirkham TC, Williams CM, Fezza F, Di Marzo V (2002) Endocannabinoid levels in rat limbic forebrain and hypothalamus in relation to fasting, feeding and satiation: stimulation of eating by 2-arachidonoyl glycerol. Br J Pharmacol 136:550-557. https://doi. org/10.1038/sj.bjp.0704767

22. Jamshidi N, Taylor DA (2001) Anandamide administration into the ventromedial hypothalamus stimulates appetite in rats. Br J Pharmacol 134:1151-1154. https://doi.org/10.1038/sj.bjp.07043 79

23. Parsons LH, Hurd YL (2015) Endocannabinoid signalling in reward and addiction. Nat Rev Neurosci 16:579-594. https://doi. org/10.1038/nrn4004

24. Di Marzo V, Goparaju SK, Wang L, Liu J, Batkai S, Jarai Z et al (2001) Leptin-regulated endocannabinoids are involved in maintaining food intake. Nature 410:822-825. https://doi.org/10.1038/ 35071088

25. Matias I, Di Marzo V (2006) Endocannabinoid system and its role in energy regulation. Expert Rev Endocrinol Metab 1:557-569. https://doi.org/10.1586/17446651.1.4.557

26. Mazier W, Saucisse N, Gatta-Cherifi B, Cota D (2015) The endocannabinoid system: pivotal orchestrator of obesity and metabolic disease. Trends Endocrinol Metab 26:524-537. https://doi.org/10. 1016/j.tem.2015.07.007

27. Slomp M, Belegri E, Blancas-Velazquez AS, Diepenbroek C, Eggels L, Gumbs MCR et al (2019) Stressing the importance of choice: Validity of a preclinical free-choice high-caloric diet paradigm to model behavioural, physiological and molecular adaptations during human diet-induced obesity and metabolic dysfunction. J Neuroendocrinol 31:e12718. https://doi.org/10.1111/jne. 12718

28. la Fleur SE, Luijendijk MC, van der Zwaal EM, Brans MA, Adan RA (2014) The snacking rat as model of human obesity: effects of a free-choice high-fat high-sugar diet on meal patterns. Int J Obes (Lond) 38:643-649. https://doi.org/10.1038/ijo.2013.159

29. la Fleur SE, Vanderschuren LJ, Luijendijk MC, Kloeze BM, Tiesjema B, Adan RA (2007) A reciprocal interaction between foodmotivated behavior and diet-induced obesity. Int J Obes (Lond) 31:1286-1294. https://doi.org/10.1038/sj.ijo.0803570

30. Pickering C, Alsio J, Hulting AL, Schioth HB (2009) Withdrawal from free-choice high-fat high-sugar diet induces craving only in obesity-prone animals. Psychopharmacology 204:431-443. https://doi.org/10.1007/s00213-009-1474-y

31. Spector AC, Smith JC (1984) A detailed analysis of sucrose drinking in the rat. Physiol Behav 33:127-136. https://doi.org/10.1016/ 0031-9384(84)90023-4

32. Paxinos G, Watson C (2007) The rat brain in stereotaxic coordinates. Academic Press, London

33. De Sa Nogueira D, Bourdy R, Filliol D, Awad G, Andry V, Goumon $Y$ et al (2021) Binge sucrose-induced neuroadaptations: A focus on the endocannabinoid system. Appetite. https://doi.org/ 10.1016/j.appet.2021.105258

34. Li B, Matter EK, Hoppert HT, Grayson BE, Seeley RJ, Sandoval DA (2014) Identification of optimal reference genes for RT-qPCR in the rat hypothalamus and intestine for the study of obesity. Int J Obes (Lond) 38:192-197. https://doi.org/10.1038/ijo.2013.86

35. Silberberg G, Baruch K, Navon R (2009) Detection of stable reference genes for real-time PCR analysis in schizophrenia and bipolar disorder. Anal Biochem 391:91-97. https://doi.org/10.1016/j. ab.2009.05.026

36. Livak KJ, Schmittgen TD (2001) Analysis of relative gene expression data using real-time quantitative PCR and the 2(-Delta Delta C(T)) Method. Methods 25:402-408. https://doi.org/10.1006/ meth.2001.1262

37. Alsio J, Olszewski PK, Norback AH, Gunnarsson ZE, Levine AS, Pickering C et al (2010) Dopamine D1 receptor gene expression decreases in the nucleus accumbens upon long-term exposure to palatable food and differs depending on diet-induced obesity phenotype in rats. Neuroscience 171:779-787. https://doi.org/10. 1016/j.neuroscience.2010.09.046

38. Decarie-Spain L, Sharma S, Hryhorczuk C, Issa-Garcia V, Barker PA, Arbour N et al (2018) Nucleus accumbens inflammation mediates anxiodepressive behavior and compulsive sucrose seeking elicited by saturated dietary fat. Mol Metab 10:1-13. https:// doi.org/10.1016/j.molmet.2018.01.018

39. Pertwee RG (2006) The pharmacology of cannabinoid receptors and their ligands: an overview. Int J Obes 30:S13-S18. https://doi. org/10.1038/sj.ijo.0803272

40. Ishiguro H, Onaivi ES, Horiuchi Y, Imai K, Komaki G, Ishikawa $\mathrm{T}$ et al (2011) Functional polymorphism in the GPR55 gene is associated with anorexia nervosa. Synapse 65:103-108. https:// doi.org/10.1002/syn.20821

41. Tuduri E, Imbernon M, Hernandez-Bautista RJ, Tojo M, Ferno J, Dieguez C et al (2017) GPR55: a new promising target for metabolism? J Mol Endocrinol 58:R191-R202. https://doi.org/ 10.1530/JME-16-0253

42. Balenga NA, Martínez-Pinilla E, Kargl J, Schröder R, Peinhaupt M, Platzer W et al (2014) Heteromerization of GPR55 and 
cannabinoid $\mathrm{CB}<\mathrm{sub}>2</$ sub $>$ receptors modulates signalling. Br J Pharmacol 171:5387-5406. https://doi.org/10.1111/bph. 12850

43. Moreno E, Andradas C, Medrano M, Caffarel MM, Perez-Gomez E, Blasco-Benito S et al (2014) Targeting CB2-GPR55 receptor heteromers modulates cancer cell signaling. J Biol Chem 289:21960-21972. https://doi.org/10.1074/jbc.M114.561761

44. Rios C, Gomes I, Devi LA (2006) mu opioid and CB1 cannabinoid receptor interactions: reciprocal inhibition of receptor signaling and neuritogenesis. Br J Pharmacol 148:387-395. https://doi.org/ 10.1038/sj.bjp.0706757

45. Rodriguez JJ, Mackie K, Pickel VM (2001) Ultrastructural localization of the CB1 cannabinoid receptor in mu-opioid receptor patches of the rat Caudate putamen nucleus. J Neurosci: Offi $\mathbf{J}$ Soc Neurosci 21:823-833. https://doi.org/10.1523/JNEUROSCI. 21-03-00823.2001

46. Pecina S, Berridge KC (2005) Hedonic hot spot in nucleus accumbens shell: where do mu-opioids cause increased hedonic impact of sweetness? J Neurosci 25:11777-11786. https://doi.org/10. 1523/JNEUROSCI.2329-05.2005

47. Soria-Gomez E, Matias I, Rueda-Orozco PE, Cisneros M, Petrosino S, Navarro L et al (2007) Pharmacological enhancement of the endocannabinoid system in the nucleus accumbens shell stimulates food intake and increases c-Fos expression in the hypothalamus. Br J Pharmacol 151:1109-1116. https://doi.org/ 10.1038/sj.bjp.0707313

48. Wei D, Lee D, Li D, Daglian J, Jung KM, Piomelli D (2016) A role for the endocannabinoid 2-arachidonoyl-sn-glycerol for social and high-fat food reward in male mice. Psychopharmacology 233:1911-1919. https://doi.org/10.1007/s00213-016-4222-0

49. Lupica CR, Riegel AC, Hoffman AF (2004) Marijuana and cannabinoid regulation of brain reward circuits. Br J Pharmacol 143:227-234. https://doi.org/10.1038/sj.bjp.0705931

50. Wang H, Treadway T, Covey DP, Cheer JF, Lupica CR (2015) Cocaine-induced endocannabinoid mobilization in the ventral tegmental area. Cell Rep 12:1997-2008. https://doi.org/10.1016/j. celrep.2015.08.041

51. De Luca MA, Valentini V, Bimpisidis Z, Cacciapaglia F, Caboni P, Di Chiara G (2014) Endocannabinoid 2-arachidonoylglycerol self-administration by sprague-dawley rats and stimulation of in vivo dopamine transmission in the nucleus accumbens shell. Front Psychiatry 5:140. https://doi.org/10.3389/fpsyt.2014.00140

52. Morozov YM, Koch M, Rakic P, Horvath TL (2017) Cannabinoid type 1 receptor-containing axons innervate NPY/AgRP neurons in the mouse arcuate nucleus. Mol Metab 6:374-381. https://doi. org/10.1016/j.molmet.2017.01.004

53. Tunbridge EM, Bannerman DM, Sharp T, Harrison PJ (2004) Catechol-o-methyltransferase inhibition improves set-shifting performance and elevates stimulated dopamine release in the rat prefrontal cortex. J Neurosci 24:5331-5335. https://doi.org/10. 1523/JNEUROSCI.1124-04.2004

54. Lapish CC, Ahn S, Evangelista LM, So K, Seamans JK, Phillips AG (2009) Tolcapone enhances food-evoked dopamine efflux and executive memory processes mediated by the rat prefrontal cortex. Psychopharmacology 202:521-530. https://doi.org/10.1007/ s00213-008-1342-1
55. Annerbrink K, Westberg L, Nilsson S, Rosmond R, Holm G, Eriksson E (2008) Catechol O-methyltransferase val158-met polymorphism is associated with abdominal obesity and blood pressure in men. Metabolism 57:708-711. https://doi.org/10.1016/j. metabol.2008.01.012

56. Dreher JC, Kohn P, Kolachana B, Weinberger DR, Berman KF (2009) Variation in dopamine genes influences responsivity of the human reward system. Proc Natl Acad Sci U S A 106:617-622. https://doi.org/10.1073/pnas.0805517106

57. Durst M, Konczol K, Balazsa T, Eyre MD, Toth ZE (2019) Reward-representing D1-type neurons in the medial shell of the accumbens nucleus regulate palatable food intake. Int $\mathrm{J}$ Obes (Lond) 43:917-927. https://doi.org/10.1038/s41366-018-0133-y

58. Oginsky MF, Maust JD, Corthell JT, Ferrario CR (2016) Enhanced cocaine-induced locomotor sensitization and intrinsic excitability of NAc medium spiny neurons in adult but not in adolescent rats susceptible to diet-induced obesity. Psychopharmacology 233:773-784. https://doi.org/10.1007/s00213-015-4157-x

59. Vollbrecht PJ, Mabrouk OS, Nelson AD, Kennedy RT, Ferrario CR (2016) Pre-existing differences and diet-induced alterations in striatal dopamine systems of obesity-prone rats. Obesity (Silver Spring) 24:670-677. https://doi.org/10.1002/oby.21411

60. Cifani C, Micioni Di Bonaventura MV, Pucci M, Giusepponi ME, Romano A, Di Francesco A et al (2015) Regulation of hypothalamic neuropeptides gene expression in diet induced obesity resistant rats: possible targets for obesity prediction? Front Neurosci 9:187. https://doi.org/10.3389/fnins.2015.00187

61. la Fleur SE, van Rozen AJ, Luijendijk MC, Groeneweg F, Adan RA (2010) A free-choice high-fat high-sugar diet induces changes in arcuate neuropeptide expression that support hyperphagia. Int J Obes (Lond) 34:537-546. https://doi.org/10.1038/ijo.2009.257

62. Levin BE (1999) Arcuate NPY neurons and energy homeostasis in diet-induced obese and resistant rats. Am J Physiol 276:R382 R387. https://doi.org/10.1152/ajpregu.1999.276.2.R382

63. Wang C, Yang N, Wu S, Liu L, Sun X, Nie S (2007) Difference of NPY and its receptor gene expressions between obesity and obesity-resistant rats in response to high-fat diet. Horm Metab Res 39:262-267. https://doi.org/10.1055/s-2007-973073

64. Kleinert M, Clemmensen C, Hofmann SM, Moore MC, Renner S, Woods SC et al (2018) Animal models of obesity and diabetes mellitus. Nat Rev Endocrinol 14:140-162. https://doi.org/10. 1038/nrendo.2017.161

65. Lutz TA (2018) Considering our methods: Methodological issues with rodent models of appetite and obesity research. Physiol Behav 192:182-187. https://doi.org/10.1016/j.physbeh.2018.02. 026

66. Bulik C, Yilmaz Z, HArdaway A (2015) Genetics and epigenetics of eating disorders. Adv Genom Genet 5:131. https://doi.org/10. 2147/AGG.S55776

67. Murphy T, Le Foll B (2020) Targeting the endocannabinoid CB1 receptor to treat body weight disorders: a preclinical and clinical review of the therapeutic potential of past and present $\mathrm{CB} 1$ drugs. Biomolecules. https://doi.org/10.3390/biom10060855 